\title{
Surveillance for COVID-19 in the English Football League 2019-2020
}

Dr. Subhashis Basu - English Football League (EFL) Occupational Medicine Advisor, Sheffield United Football Club, Firshill Crescent, Shirecliffe, Sheffield, S4 7DR

Dr. Richard Higgins - Lead Sports Physician for the North and English Football League (EFL) Medical Advisor, English Institute of Sport, Coleridge Road, Sheffield, England, S9 5DA

Dr. Aneil Malhotra - Division of Cardiovascular Science, University of Manchester, Manchester University NHS Foundation Trust, England, M13 9PL

Dr Imtiaz Ahmad - Head of Medical Services, Queens Park Rangers Football and Athletic Club, Shepherd's Bush, London, England, W12 7PJ

Correspondence to:

Dr.Subhashis Basu

Sheffield United Football Club, Firshill Crescent, Shirecliffe, Sheffield, S4 7DR

Email: Subhashis.basu@nhs.net 


\begin{abstract}
Medical surveillance and risk mitigation protocols to reduce viral transmission have underpinned the return of elite football during the COVID-19 pandemic. This article describes the evidence-informed approach and surveillance findings from the English Football League across a 9-week period at the end of the 2019-20 season. Protocols were devised by the lead EFL Medical Advisor with specialist occupational medicine input. Isolation requirements for cases and contacts were in-line with UK Government regulations, with external contact tracing conducted by local public health authorities. Quantitative PCR testing was conducted twice weekly and within 72 hours of fixtures. 43 individuals, including 18 players returned positive tests. No positive results were returned after week 5 (round 10). Our findings support those from other leagues that with appropriate compliance, elite football can continue safely during this pandemic. We recommend that protocols and compliance should be revised as necessary according to community prevalence and changes in viral transmission dynamics.
\end{abstract}

Keywords: Surveillance, COVID, Football, Infection, Professional, PCR, Elite 


\section{Introduction}

Medical surveillance for COVID-19 has underpinned the return of elite football in several countries.

${ }^{1,2}$ Central aspects to enabling safe restarts include risk assessment matrices for mitigating transmission within training grounds and stadia, symptom surveillance using questionnaires, physical examination where appropriate, as well as diagnostic tests. Measures to mitigate SARS-COV-2 transmission are consistent with wider occupational health strategies including physical distancing, use of facial coverings, optimising environmental conditions including ventilation, humidity, and temperature, stringent surface cleaning as well as attention to personal hygiene. ${ }^{3}$ Although advancing age is established as the primary risk factor for hospitalisation and mortality, demographic differences such as ethnicity and gender, as well as underlying health complaints including respiratory disorders, diabetes and kidney disease are associated with an increased risk of severe illness at all age groups. ${ }^{4}$ Symptoms include fever, a new continuous cough, anosmia and ageusia. Nonetheless, headache, myalgia, fatigue, and loss of appetite including missed meals have also been associated with increased odds of a positive SARS-COV-2 test, particularly in younger individuals. ${ }^{5}$ Persistence of fatigue, breathlessness, myalgia, cough, and autonomic disturbances has also been identified in about $10 \%$ of individuals following infection. ${ }^{6}$ Asymptomatic illness has been documented in several studies but with a lower risk of transmission than from symptomatic individuals. ${ }^{7}$

Diagnostic tests allow the early identification and isolation of infected individuals, of which quantitative PCR (RT-qPCR) is the most widely used in elite sport. Results from rapid lateral-flow devices may also aid clinical decision-making, but published evaluations report modest sensitivity for antigen tests and limited specificity for antibody tests. ${ }^{8,9}$ The application, timing and interpretation is informed by the natural course of the disease. Shedding of live virus from symptomatic individuals decreases substantially following the first week of symptoms, with studies failing to culture live virus in mild cases beyond day 9 of symptoms. ${ }^{10,11}$ In many individuals even without severe symptoms, the detection of viral RNA has been shown to persist for considerably longer than the shedding of live virus in different specimen types, meaning that although they continue to have a positive PCR, they are unlikely to be infectious. ${ }^{12,13}$ Data suggest that the median incubation period of COVID -19 is 5 days, with $97.5 \%$ of those developing symptoms doing so within 11 days, and this has informed the wider public health management of COVID-19 contacts. ${ }^{14}$ There are currently very few reports of 
reinfection within 3 months of the first episode of illness. ${ }^{15,16}$ This article describes the findings from PCR surveillance during the final weeks of the EFL Championship Season 2019-2020.

\section{Methods}

The first protocols for the interpretation and management of PCR results in the English Football League (EFL) were devised in May 2020 by the authors of the paper (Table 1). These were developed in tandem with a detailed risk assessment template provided to all clubs which provided recommendations as to how to reduce transmission risks including physical distancing outside of onpitch training activity, reducing congregation in enclosed environments for example by staggering activity, use of facial coverings in indoor settings, daily symptom screening, promotion of personal hygiene and stringent cleaning practices in training grounds and stadia. Areas of transmission concern included travel by car, bus, train, or air, changing rooms, dining areas and team meetings including video analysis. Emphasis was placed on early symptom recognition and isolation of cases and contacts. A broad spectrum of complaints was included on the daily symptom questionnaire including fever, cough, loss of smell or taste, new onset headache, loss of appetite, fatigue, myalgia as well as abdominal complaints. The protocols were developed by the lead EFL Medical Advisor with professional occupational medicine input. Isolation requirements for cases and contacts were mandated by Public Health England. Risk assessments were ratified by the Department for Digital, Culture, Media \& Sport of the United Kingdom Government.

Contact tracing within clubs was conducted by the team doctor in conjunction with RH and SB. All positive cases and in-club contacts were reported to local public health authorities, who were also responsible for identification of relevant contacts in the community. Timescales for isolation for cases and contacts were in accordance with English Government requirements. Cases amongst nonplaying staff were managed in an equivalent manner. Recommendations for return to play were based on expert virology, cardiology, and occupational medicine advice, such as that of the prevention of long-term sequelae such as myocarditis and risk mitigation measures within the environment. ${ }^{17,18}$ To allow clinicians to remain autonomous, these guidelines were not mandatory but regularly updated considering new data. The intention was to support medical teams in making evidence-based decisions regarding a safe return to play and address resistance from team officials wishing to expedite a return. 


\begin{tabular}{|c|c|}
\hline $\begin{array}{c}\text { A. Mild symptoms (coryzal } \\
\text { only) at time of positive PCR } \\
\text { test }\end{array}$ & $\begin{array}{l}\text { - Minimum exclusion of } 10 \text { days from start of symptoms (return } \\
\text { day 11) AND must also be } 48 \text { hours without symptoms before } \\
\text { return to training (excluding cough, anosmia, ageusia which may } \\
\text { persist) } \\
\text { - } \begin{array}{l}\text { Activity levels during exclusion and return-to-play protocol under } \\
\text { direction of club doctor - consider graded return. Expert opinion } \\
\text { guidance available }{ }^{17,18}\end{array} \\
\text { - Consider medical investigations if symptoms recur and of clinical } \\
\text { concern, which may include cardiac assessment (see below } \\
\text { section B) } \\
\text { Exclude from testing pool following positive test * } \\
\text { Players should not be retested prior to return to play }\end{array}$ \\
\hline $\begin{array}{l}\text { B. Moderate symptoms** at } \\
\text { time of positive PCR test }\end{array}$ & $\begin{array}{l}\text { - Minimum exclusion of } 10 \text { days from start of symptoms (return } \\
\text { day 11) AND must also be } 48 \text { hours without symptoms before } \\
\text { return to training (excluding cough, anosmia, ageusia which may } \\
\text { persist) } \\
\text { - } \quad \text { Refrain from all physical activity during exclusion period } \\
\text { - Consider specialist medical advice before return to play. Medical } \\
\text { investigations may include bloods (FBC, U\&E, Troponin-I and } \\
\text { CRP) and ECG for all players, and respiratory evaluation before } \\
\text { graded return . } \\
\text { Return-to-play protocol under direction of club doctor. Expert } \\
\text { opinion guidance available } 17,18 \\
\text { - If symptoms recur during graded return - stop all activity and } \\
\text { consider investigations as above and/or any other clinically- } \\
\text { indicated tests. Can return to training when club doctor deems } \\
\text { appropriate to do so. } \\
\text { Exclude from testing pool following positive test* } \\
\text { Players should not be retested prior to return to play }\end{array}$ \\
\hline $\begin{array}{l}\text { C. Asymptomatic at time of } \\
\text { positive PCR test }\end{array}$ & $\begin{array}{l}\text { - } \quad \text { Exclude for } 10 \text { days from date of test } \\
\text { - } \quad \text { Activity levels during exclusion and return-to-play protocol under } \\
\text { direction of club doctor - consider graded return. Expert opinion } \\
\text { guidance available } 17,18 \\
\text { - } \quad \text { Players can return to training ground after } 10 \text { days if no } \\
\text { symptoms develop. } \\
\text { - If symptoms develop players should stop training and manage } \\
\text { - } \text { according to A or B above (restart pathway) } \\
\text { - Players should not be retested prior to return to play }\end{array}$ \\
\hline
\end{tabular}




\begin{tabular}{|c|c|}
\hline $\begin{array}{c}\text { D. Symptomatic but negative at } \\
\text { time of PCR test }\end{array}$ & $\begin{array}{l}\text { - Manage accordingly to clinical judgement. } \\
\text { - If COVID-19 strongly suspected despite negative test(s) manage } \\
\text { according to A or B above. Consider repeat PCR } 48-72 \text { hours later }\end{array}$ \\
\hline $\begin{array}{l}\text { E. Household member PCR } \\
\text { positive but player PCR } \\
\text { negative and asymptomatic }\end{array}$ & $\begin{array}{l}\text { - } \text { Exclusion period in line with UK Government requirements } \\
\text { - } \quad \text { Can continue with normal training activities during isolation } \\
\text { - If becomes symptomatic - consider PCR test and manage } \\
\text { accordingly }\end{array}$ \\
\hline
\end{tabular}

Table 1: Framework for interpretation and Management of PCR Testing in Sport

*Exclusion for up to 90 days ${ }^{7,8}$

**Moderate symptoms include fever, cough, shortness of breath, anosmia, ageusia without hospitalisation

The remaining games in the EFL Championship 2019-20 season were completed, but League 1 and League 2 games curtailed for financial reasons. A biweekly testing regime was chosen to balance potential risks to health against costs of delivering the scheme. Tests were conducted within 72 hours before any league fixture to minimise the possibility of transmission by asymptomatic or pauci-symptomatic individuals in the early stages of illness as far as reasonably practical. It was intended that the programme would also help reinforce the importance of behavioural changes within clubs, through the risk of incurring a positive test through indiscretion, and further our knowledge regarding the prevalence of illness in professional football.

\section{Results}

In total, 21635 tests were conducted across 18 rounds over 9 weeks for all 24 EFL Championship teams. 43 individuals returned positive PCR results during this time, including 18 players and the remainder team staff. No positive cases were detected after round 10 (end of week 5). Positive cases were followed up by RH and SB with club doctors. Of the 24 clubs tested, 3 clubs had no cases; 11 clubs had 1 case, 3 clubs had 2 cases; 3 clubs had 4 cases, and 1 had 5 cases. Three cases were symptomatic at the time of detection with headache and myalgia, of which one also reported fever and cough. No player or staff member required hospital attention or community medical treatment 
at the time of illness. All made a full recovery, and none required further medical cardiopulmonary investigation. In the club that recorded 5 cases, 4 could be linked to an outbreak detected in round 4. On backwards contact tracing, this cluster was linked to a group of players that had had contact with an infected individual in the community. The cases were quickly identified in conjunction with the club doctor and immediately isolated for a 10-day period. In-club contact tracing found no significant interactions between the 4 individuals and other club members beyond normal training activities. Subsequent rounds demonstrated no evidence of further in-club transmission.

\section{Discussion}

The PCR surveillance findings confirm that elite football can continue safely during a pandemic with compliance to detail protocols which mitigate transmission risks within training grounds and stadia. The cornerstones of these protocols are to minimise person-to-person contact, limit time and numbers in areas where players and staff are likely to congregate and promote environmental conditions which reduce infection risks including optimising ventilation and humidity. Our findings are consistent with those from the German Bundesliga and Qatar Stars League, despite significantly differing SARS-COV-2 community prevalence between the countries at the time of restart. ${ }^{1,2}$ In contrast to our approach, both leagues included a quarantine period prior to re-commencing training, of 1 and 2 weeks, respectively. This was considered by the EFL but given the low community prevalence at the time of restart, and the absence of a wider community lockdown in wider society, players were alternatively advised to reduce their community interactions to as low as reasonably practical. It is possible that a stricter quarantine could have further reduced cases in the early weeks of return.

Considering these results and data from other leagues where available, a review of the surveillance program took place before the 2020-21 season, including PCR testing frequency which involves a balance between screening individuals as early as possible to prevent transmission against resource constraints. A reduced testing frequency programme focussing on testing symptomatic individuals and high exposure activities has been introduced, with mandated PCR testing for all playing and team officials following international breaks and holiday periods including Christmas and New Year given the increased risk from community interactions and travel. Protocols as well as recommendations for testing continue to be regularly updated with respect to changes in 
community disease prevalence and viral transmission dynamics with expert medical and scientific support. Whilst not the only approach in use across elite sport, we believe this management strategy to be pragmatic and broadly applicable where PCR testing may be used judiciously as a surveillance mechanism to provide additional reassurance regarding participants' health and safety.

Contributorship: $R H$ and SB developed the testing protocol. SB wrote the paper with $R H, A M$ and IA.

Conflicts of Interest: None

References

1. Meyer T, Mack D, Donde K, Harzer O, Krutsch W, Rössler A, Kimpel J, Von Laer D, Gärtner BC. Successful return to professional men's football (soccer) competition after the COVID-19 shutdown: a cohort study in the German Bundesliga. British journal of sports medicine 2020; 24:55: 62-6.

2. Schumacher YO, Tabben M, Hassoun K, Al Marwani A, Al Hussein I, Coyle P, Abbassi AK, Ballan HT, Al Kuwari AJ, Chamari K, Bahr R. Resuming professional football during the Covid-19 pandemic in a country with high infection rates A prospective cohort study. medRxiv. 2020.

3. Cevik M, Bamford C, Ho A. COVID-19 pandemic-A focused review for clinicians. Clinical Microbiology and Infection 2020; 26:7, 842-847.

4. Williamson E, Walker AJ, Bhaskaran KJ, Bacon S, Bates C, Morton CE, Curtis HJ, Mehrkar A, Evans D, Inglesby P, Cockburn J. OpenSAFELY: factors associated with COVID-19-related hospital death in the linked electronic health records of 17 million adult NHS patients. medRxiv. 2020.

5. Poletti P, Tirani M, Cereda D. Probability of symptoms and critical disease after SARS-CoV-2 infection. arRxiv 2020; Published online June 22. https://arxiv.org/abs/2006.08471v2 (preprint, version 2)

6. Menni C, Valdes A, Freidin MB. Real-time tracking of self-reported symptoms to predict potential COVID-19. Nat Med 2020. 26: 1037-1040.

7. Byambasuren O, Cardona M, Bell K, Clark J, McLaws M-L, Glasziou P. Estimating the extent of asymptomatic COVID-19 and its potential for community transmission: systematic review and metaanalysis. J Assoc Med Microbiol Infect Dis Can 2020; published online Oct 9. https://doi.org/10.3138/iammi-2020-0030

8. Wise J. Covid-19: Safety of lateral flow tests questioned after they are found to miss half of cases. BMJ 2020; 371:m4744. doi:10.1136/bmj.m4744 pmid:33277265

9. Li Z, Yi Y, Luo X. Development and clinical application of a rapid IgM-IgG combined antibody test for SARS-CoV-2 infection diagnosis. J Med Virolgy 2020. [Epub ahead of print]. doi:10.1002/jmv.25727 pmid:32104917. 
10. He X, Lau EH, Wu P, Deng X, Wang J, Hao X, Lau YC, Wong JY, Guan Y, Tan X, Mo X. Temporal dynamics in viral shedding and transmissibility of COVID-19. Nature medicine 2020; 26:672-5.

11. Midgley CM, Kujawski SA, Wong KK, Collins, JP, Epstein L, Killerby ME et al. (2020). Clinical and Virologic Characteristics of the First 12 Patients with Coronavirus Disease 2019 (COVID-19) in the United States. Nat Med 2020 26:861-868.

12. Li N, Wang X, Lv T. Prolonged SARS-CoV-2 RNA Shedding: Not a Rare Phenomenon. J Med Virol 2020; 10.1002/jmv.25952

13. Xiao F, Sun J, Xu Y, Li F, Huang X, Li H, et al. Infectious SARS-CoV-2 in Feces of Patient with Severe COVID-19. Emerg Infect Dis 2020; 26:10.3201.

14. Lauer SA, Grantz KH, Bi Q, Jones FK, Zheng Q, Meredith HR, Azman AS, Reich NG, Lessler J. The incubation period of coronavirus disease 2019 (COVID-19) from publicly reported confirmed cases: estimation and application. Annals of internal medicine 2020; 172:577-82.

15. Mahase E. Covid-19: What do we know about "long covid"?. British Medical Journal 2020;370.

16. KK-W, Hung IF-N, Ip JD, et al. COVID-19 re-infection by a phylogenetically distinct SARS-coronavirus2 strain confirmed by whole genome sequencing. Clin Infect Dis 2020; ciaa1275. Available at https://doi.org/10.1093/cid/ciaa1275.

17. Elliott N, Martin R, Heron N, et al Infographic. Graduated return to play guidance following COVID-19 infection British Journal of Sports Medicine 2020; Available at doi: 10.1136/bjsports-2020-102637

18. Bhatia RT, Marwaha S, Malhotra A, Iqbal Z, Hughes C, Börjesson M, Niebauer J, Pelliccia A, Schmied C, Serratosa L, Papadakis M. Exercise in the Severe Acute Respiratory Syndrome Coronavirus-2 (SARSCoV-2) era: A Question and Answer session with the experts Endorsed by the section of Sports Cardiology \& Exercise of the European Association of Preventive Cardiology (EAPC). European Journal of Preventive Cardiology 2020; 2047487320930596. 